\title{
Simulation analysis of a passive containment cooling system based on the RELAP5 program
}

\author{
Likai Fei* ${ }^{*}$, Shengjun Zhang, Feng Shen, Bin Gao, Xianke Meng, Dandan He \\ State Power Investment Corporation Research Institute \\ State Power Investment Corporation Research Institute, South Zone of the Future Science \& Technology Park, Beijing, 102209, \\ China
}

\begin{abstract}
Based on previous proposals for a new type of nuclear power plant with passive containment heat transfer following an accident, this work utilizes the RELAP5 program to establish a thermal hydraulic model test system. Focusing on a test circuit with a single natural circulation loop, a parameter sensitivity analysis was performed by changing parameters, such as ambient pressure, ambient temperature, and degree of surface undercooling, and the design boundary conditions for a single natural circulation test circuit were obtained. Employing a comprehensive natural circulation test circuit, the heat transfer capability of the air-cooling system of the integrated test system was evaluated by assuming parameters such as the cold source ambient temperature, providing an important reference for the design of the main equipment.
\end{abstract}

Keywords: passive cooling system, natural circulation, simulation calculation, RELAP5

\section{Introduction}

In a nuclear power plant, containment is the final safety barrier, preventing the release of radioactive fission products. In the event of an accident, removing heat from the containment is crucial to ensure the integrity of the containment. Currently, nuclear power plants require an active intervention system after 72 hours to protect the shell from the heat load; thus, research groups have focused on long-term improvements for the passive residual heat removal capacity of a nuclear power plant after an accident. This study considers the implementation of a previously proposed project based on a time-unlimited passive in-shell cooling system. The system primarily consists of a built-in heat exchanger, external air cooler, riser, and descending section. After an accident, the steam in the containment will condense on the outer surface of the built-in heat exchanger and heat the cooling medium inside the pipe. The external air cooler acts as a cooling source to produce a height difference for the built-in heat exchanger; thus, resulting in natural circulation. The system circulates the heat out of the containment through the natural circulation circuit.

Before a time-unlimited system design is used, its application must be verified by via experimental tests. This article primarily focuses on an integrated test bench simulation of a single natural circulation loop. For a single natural circulation loop, the heat transfer coefficient is determined by the degree of surface undercooling [1,2]; then, the accuracy of the heat transfer coefficient is verified by comparing the calculated degree of undercooling with the input conditions. Next, the circulating flow rate is calculated to determine the test circuit boundary conditions, using a single natural circulation test circuit as the foundation. For an integrated natural circulation loop, the heat transfer capability of the air cooler is evaluated by assuming the given boundary conditions. The calculation results can guide well in terms selecting the equipment for a test circuit and development of the test process.

\footnotetext{
* Manuscript received March 5, 2018; revised January 14, 2019.

Corresponding author. E-mail address: feilikai@spic.com.cn.

doi: $10.12720 /$ sgce.8.2.184-190
} 


\section{System Modeling}

\subsection{Introduction of the RELAP5 program}

RELAP5/MOD3.4 is a well-known thermal hydraulic estimation program designed by the Idaho National Engineering Laboratory with the assistance of the Nuclear Regulatory Commission. The program can be utilized to calculate and analyze support regulations, license audits, accident mitigation measures, operational guidelines, and pilot programs.

In this study, RELAP5 is used for the transient analysis of a nuclear power plant system. As shown in Fig. 1, the RELAP5 actuator includes a control body, steady-state equation, hydraulic components, hot components, logic signals, and a control system, in addition to numerous common component models, such as models for pipes, valves, pumps, hot components, electric heating components, steam turbines, and water separators. Moreover, many special process models are included, such as those for a rapid enlargement of pipe area, pipe valve resistance, branch flow, critical flow, boron tracking, and non-condensable gas transport. The program has also passed the LOFT, PBF, NRU, ACRR, and Semiscale tests, among others[3,4].

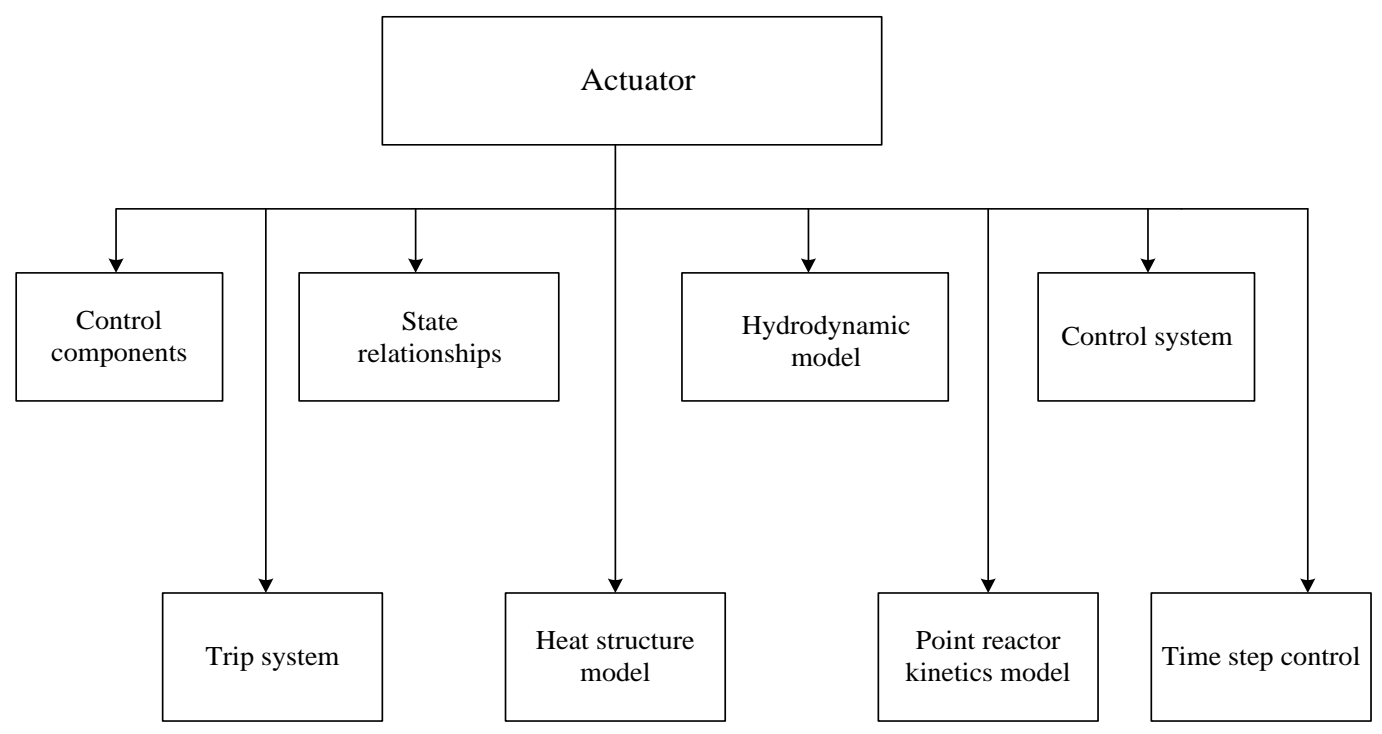

Fig. 1. RELAP5 transient calculation module

\subsection{Individual test loop modeling}

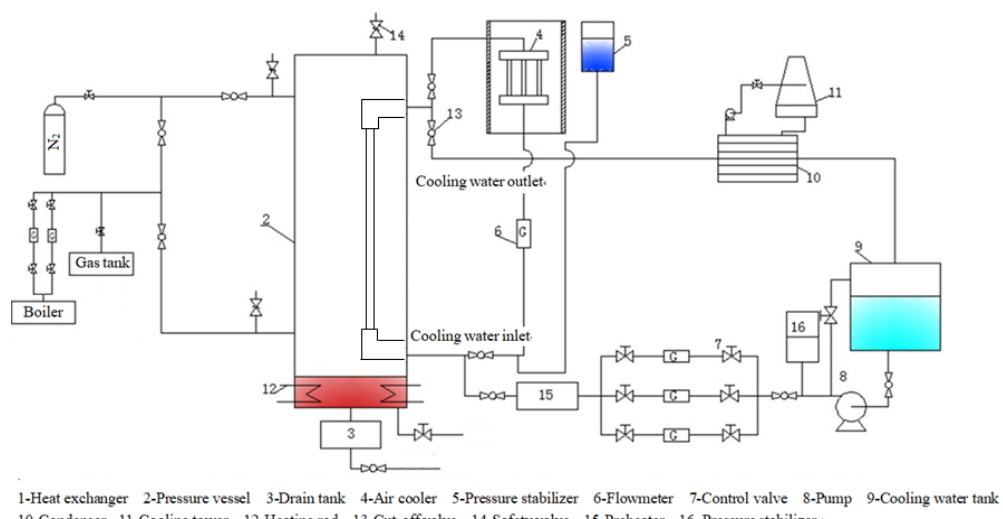

10-Condenser 11-Cooling tower 12-Heating rod 13-Cut-off valve 14-Safety valve 15-Preheater 16-Pressure stabilizer-

Fig. 2. Schematic of a test bench time-unlimited passive cooling system 
Figure 2 shows a diagram of a single test circuit. The system primarily consists of five parts, including a test-bed air supply system, external condensation test section, natural circulation circuit, test section cooling circuit, and data acquisition system. The single natural circulation loop includes a single-tube test section, ascending section, external air cooler, and descending section.

The single natural circulation loop includes a single-tube test section, ascending section, external air cooler, and descending section. Heating element 102 of the heating section is located under the circuit as shown in red, in Fig. 3. The temperature of the containment is assumed to be constant, and the temperature exotherm of element 102 is at the temperature-bounding boundary. Hot section 106 of the cooling section is located above the loop, as shown in blue in Fig. 3. Pipe 103 (ascending section) and Pipe 107 (descending section) are used to adjust the height of the loop based on the calculated heat transfer characteristics of the natural circulation loop at different heights. In the test circuit, the pipes are identical based on the designed size, and the local loss coefficient is determined from an empirical coefficient in fluid mechanics. As a single-phrase coolant is used, if a two-phase flow is involved, the method of correction based on a single-phase flow[5,6] is adopted.

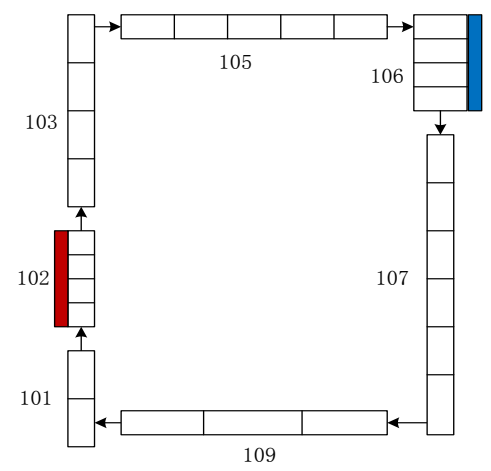

Fig. 3. Single natural circulation loop for the RELAP5 node

\subsection{Integrated test circuit modeling and analysis}

The integrated test circuit differs from the single test circuit because the test section in the integrated natural circulation test circuit adopts a built-in heat exchanger instead of a single-tube test section, as shown in Fig. 4, which requires an external air cooler to provide a sufficient cold source. Therefore, the integrated test circuit is used to evaluate the external air cooler heat exchange capacity, providing a basis for the design of the air cooler.

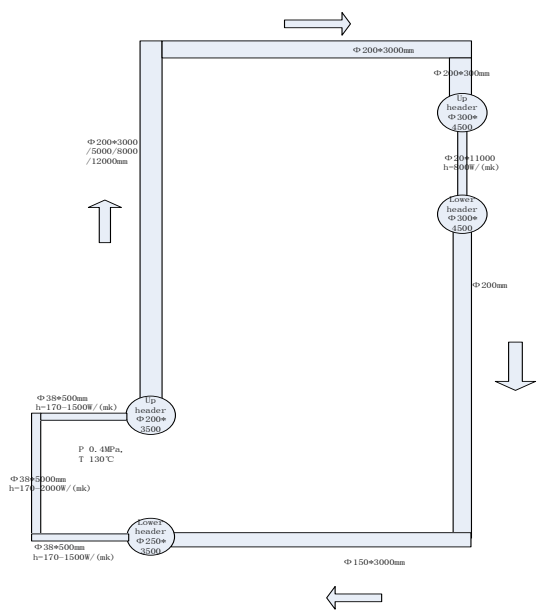

Fig. 4. Diagram of the integrated natural circulation loop 
A diagram of the integrated natural circulation loop RELAP5 node is shown in Fig. 5. The heating section is termed Pipe 102, the cooling section consists of Pipe 110 and Pipe 210, the rising section is denoted Pipe 104, the descending section corresponds to Pipe 112, and the header is equivalent to the branch. As with the model for a single natural circulation loop, the pipelines are equivalent in design size, and the local loss coefficients are determined from empirical fluid mechanics coefficients.

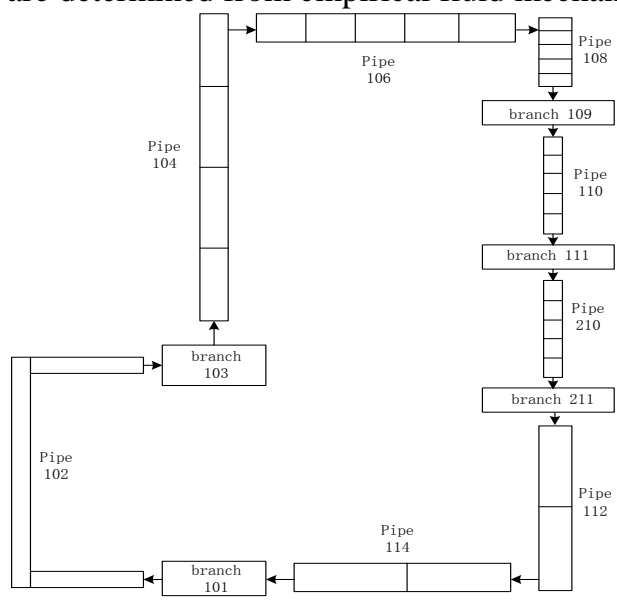

Fig. 5. Diagram of the integrated natural circulation loop RELAP5 node

\section{Simulation Result Analysis}

\subsection{Single test circuit calculation results}

To determine the boundary area of the single test circuit, a pressure of $0.2 \mathrm{MPa}$ and a containment pressure of 0.6 MPa were simulated. The heat transfer coefficient was calculated by the Dehbi equation. The input conditions and calculation results are shown in Table 1.

Table 1 Results for different pressures and temperatures

\begin{tabular}{|c|c|c|c|}
\hline Test conditions & & ut conditions & Calculation results \\
\hline \multirow{10}{*}{$\begin{array}{c}0.2 \mathrm{MPa}, \text { Steam } \\
\text { temperature of } \\
99.68^{\circ} \mathrm{C}\end{array}$} & $\begin{array}{l}\text { Undercooling of the } \\
\text { wall }\left({ }^{\circ} \mathrm{C}\right)\end{array}$ & Heat transfer coefficient $\mathrm{W} /\left(\mathrm{m}^{2} \cdot \mathrm{K}\right)$ & Undercooling of the wall $\left({ }^{\circ} \mathrm{C}\right)$ \\
\hline & 15 & 402.4004 & 28.841 \\
\hline & 20 & 374.4758 & 29.563 \\
\hline & 25 & 354.1573 & 30.115 \\
\hline & 30 & 338.3771 & $30.561 *$ \\
\hline & 35 & 325.5849 & 30.934 \\
\hline & 40 & 314.8953 & 31.255 \\
\hline & 45 & 305.7582 & 31.535 \\
\hline & 50 & 297.8096 & 31.882 \\
\hline & 60 & 284.5401 & 32.209 \\
\hline \multirow{10}{*}{$\begin{array}{c}0.2 \mathrm{MPa}, \text { Steam } \\
\text { temperature of } \\
115.69^{\circ} \mathrm{C}\end{array}$} & $\begin{array}{l}\text { Undercooling of the } \\
\text { wall }\left({ }^{\circ} \mathrm{C}\right)\end{array}$ & Heat transfer coefficient $\mathrm{W} /\left(\mathrm{m}^{2} \cdot \mathrm{K}\right)$ & Undercooling of the wall $\left({ }^{\circ} \mathrm{C}\right)$ \\
\hline & 15 & 1262.5 & 24.244 \\
\hline & 20 & 1174.9 & 25.179 \\
\hline & 25 & 1111.1 & $25.908 *$ \\
\hline & 30 & 1061.6 & 26.496 \\
\hline & 35 & 1021.5 & 27.015 \\
\hline & 40 & 988 & 27.452 \\
\hline & 45 & 959.3 & 27.846 \\
\hline & 50 & 934.4 & 28.196 \\
\hline & 60 & 892.7 & 28.803 \\
\hline \multirow{2}{*}{$\begin{array}{c}0.6 \mathrm{MPa}, \text { Steam } \\
\text { temperature of } \\
115.15^{\circ} \mathrm{C}\end{array}$} & $\begin{array}{l}\text { Undercooling of the } \\
\text { wall }\left({ }^{\circ} \mathrm{C}\right)\end{array}$ & Heat transfer coefficient $\mathrm{W} /\left(\mathrm{m}^{2} \cdot \mathrm{K}\right)$ & Undercooling of the wall $\left({ }^{\circ} \mathrm{C}\right)$ \\
\hline & 15 & 599 & $\begin{array}{l}34 \\
36\end{array}$ \\
\hline
\end{tabular}




\begin{tabular}{|c|c|c|c|}
\hline \multirow{11}{*}{$\begin{array}{c} \\
\\
0.6 \mathrm{MPa}, \text { Steam } \\
\text { temperature of } \\
155.46^{\circ} \mathrm{C}\end{array}$} & $\begin{array}{l}25 \\
30 \\
35 \\
40 \\
45 \\
50 \\
60\end{array}$ & $\begin{array}{l}441 \\
395 \\
360 \\
332 \\
310 \\
291 \\
261 \\
\end{array}$ & $\begin{array}{c}38 \\
40 \\
42 \\
41.808^{*} \\
42.337 \\
43.2 \\
44.4\end{array}$ \\
\hline & $\begin{array}{l}\text { Undercooling of the } \\
\text { wall }\left({ }^{\circ} \mathrm{C}\right)\end{array}$ & Heat transfer coefficient $\mathrm{W} /\left(\mathrm{m}^{2} \cdot \mathrm{K}\right)$ & Undercooling of the wall $\left({ }^{\circ} \mathrm{C}\right)$ \\
\hline & 15 & 4419.9 & 20.7 \\
\hline & 20 & 3996.5 & 22.288 \\
\hline & 25 & 3696.3 & $23.546^{*}$ \\
\hline & 30 & 3467.8 & 25 \\
\hline & 35 & 3285.6 & 25.471 \\
\hline & 40 & 3135.6 & 26.299 \\
\hline & 45 & 3009 & 27 \\
\hline & 50 & 934.4 & 27.6 \\
\hline & 60 & 892.7 & 28.8 \\
\hline
\end{tabular}

The external pressure of the pipe is $0.2-0.6 \mathrm{MPa}$, which includes all experimental operating points for a single natural circulation circuit. To calculate the accuracy, this study determines the heat transfer coefficient for the case of wall undercooling, and then, the model results and the calculated wall undercooling based on the input conditions are compared. When the results are consistent, a more accurate heat transfer coefficient is obtained, and the natural circulation flow is calculated, as shown in Table 2.

Table 2 Natural circulation flow under different test conditions

\begin{tabular}{cc}
\hline Test conditions & Natural circulation flow $(\mathrm{kg} / \mathrm{s})$ \\
\hline $0.2 \mathrm{MPa}$, Steam temperature $99.68^{\circ} \mathrm{C}$, Undercooling $30^{\circ} \mathrm{C}$ & 0.21 \\
$0.2 \mathrm{MPa}$, Steam temperature $115.69^{\circ} \mathrm{C}$, Undercooling $25^{\circ} \mathrm{C}$ & 0.14 \\
$0.6 \mathrm{MPa}$, Steam temperature $99.68^{\circ} \mathrm{C}$, Undercooling $40^{\circ} \mathrm{C}$ & 0.23 \\
$0.6 \mathrm{MPa}$, Steam temperature $155.46^{\circ} \mathrm{C}$, Undercooling $25^{\circ} \mathrm{C}$ & 0.54
\end{tabular}

Table 2 presents the natural circulation flow calculated when the distance between the heating section and the center of the cooling section is $3 \mathrm{~m}$. The height difference between the natural circulation loop and the cold and heat sources affects the natural circulation. Therefore, sensitivity analysis is performed for the height difference. In this study, a pressure of $0.6 \mathrm{MPa}$, steam temperature of $155.46^{\circ} \mathrm{C}$, and height difference of 3, 9, and $12 \mathrm{~m}$ are applied, and the calculation results are shown in Fig. 6. A larger height difference corresponds to a greater degree of supercooling for the wall at a given heat transfer coefficient; more heat is transferred across a constant area. Similarly, a larger altitude difference corresponds to a larger generated driving force and a greater natural circulation capacity.

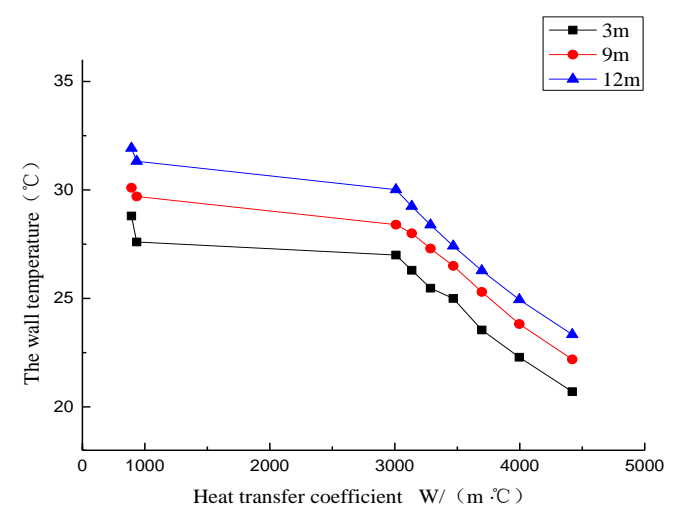

Fig. 6. Effect of the natural circulation height difference on wall undercooling 


\subsection{Comprehensive analysis of the test circuit results}

To evaluate the heat transfer capacity of the natural circulation loop in the integrated test, this paper assumes a pressure of $0.4 \mathrm{MPa}$, a containment steam temperature of $112.3^{\circ} \mathrm{C}$, and a cold source ambient temperature (atmospheric temperature) of $40^{\circ} \mathrm{C}, 45^{\circ} \mathrm{C}$, and $50^{\circ} \mathrm{C}$. Under these conditions, the test circuit flow and heat transfer were evaluated, as shown in Fig. 7.

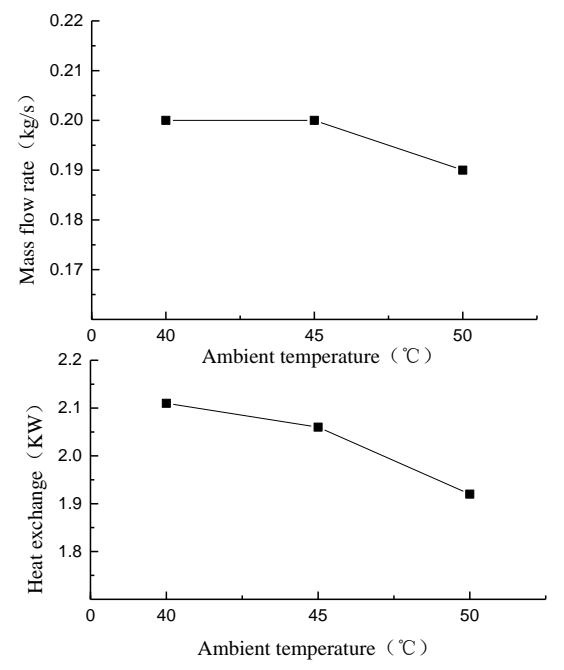

Fig. 7. Mass flow rate and heat exchange as a function of ambient temperature

The total heat exchange capacity of the experiment is designed to be $750 \mathrm{~kW}$. For a cold source ambient temperature of $40^{\circ} \mathrm{C}$, the heat exchange capacity of the air cooler is $2.11 \mathrm{~kW}$, which requires 356 tubes. For a cold source ambient temperature of $50^{\circ} \mathrm{C}$ and a single-tube heat exchange capacity of 1.92 $\mathrm{kW}, 390$ pipes are required.

\section{Conclusion}

Using RELAP5 modeling and calculation, the design boundary conditions of a single natural circulation test circuit can be determined. The selection of equipment for a single natural circulation loop has a quantitative influence on the boundary conditions for the test parameters.

For a single natural circulation loop, a sensitivity analysis of the natural circulation height difference is performed via simulations. The results demonstrate that a greater height difference in the natural circulation corresponds to a greater heat exchange capacity, but its added value decreases. By considering the test conditions and selecting an appropriate natural circulation height, the model provides a guide for the design of natural circulation circuits.

For an integrated natural circulation circuit, the influence of the cold source parameters on the test circuit heat transfer is calculated. As the ambient temperature increases, the heat transfer capacity decreases. The calculation results provide a reference for the design of primary equipment components.

\section{Acknowledgments}

This work is supported by the National Science and Technology Major Project of the Ministry of Science and Technology of China (2017ZX06004002).

\section{References}

[1] Su JQ, Sun ZN, Fan G.M, Ding M, Fan GM. Analysis of experiments for the effect of noncondensable gases onsteam condensation over a vertical tube external surface under lowwall subcooling. Nuclear Engineering and Design, 2014; 278 
644-650.

[2] Shen F, Zhang SJ. The Theoretical Analysis for Ultimate Passive Containment Cooling System of Nuclear Power Plant. In: Proc. of the 14th National Reactor Thermal and Fluid, 2015, Beijing.

[3] Carison KE, etal. RELAP5/MOD Code Manual, vol III: Developmental Assessment Problems, NUREG/CR-5535, EGG-2596, EG\&G Idaho, Inc.Idaho Falls, Idaho, June. 1990.

[4] The RELAP5 Code Development Team. RELAP5 code manual. America: Idaho National Engineering Laboratory, 1995.

[5] Moore RL, etal., RELAP5/MOD3 Code Manual, vol VII: Summaries and Reviews of Independent Code Assessment Reports, formally NUREG/CR-5535, SCIENTECH, Inc.,Rockville, Maryland, Idaho Falls, Idaho, March, 1998.

[6] Kumar N, Kannan N, Doshi JB, Vijayan PK. Investigations on single-phase natural circulation loop dynamics part1: Model for simulating start-up from rest. Progress in Nuclear Energy, 2014; 76: 148-159. 